\title{
A psychiatric clinic for the single homeless in a primary care setting in Inner London
}

\author{
P. L. A. JosePh, Senior Research Fellow in Forensic Psychiatry, Institute of Psychiatry, \\ London, and Visiting Psychiatrist, Great Chapel Street Medical Centre, \\ 13 Great Chapel Street, London W1V 7AL (correspondence); J. A. BRIDGEWATER, \\ Resident Medical Officer, Wytham Hall, London W9 2QJ; S. S. RAMSDEN, \\ General Practitioner, Great Chapel Street Medical Centre; and D. J. EL KABIR, \\ Physician-in-Charge, Great Chapel Street Medical Centre
}

It is well recognised that there is an increased psychiatric morbidity, in particular psychosis, personality disorder and substance abuse, among the single homeless (Lodge Patch et al, 1971). The reasons for this are complex. There is evidence that these people are mentally ill before becoming homeless and that their illness may be a cause of their homelessness. In a study of newly presenting patients at the DHSS Reception Centre in Camberwell, London, Tidmarsh \& Wood found that $87 \%$ of those with mental illness had been staying recently with their families just before their first hospital admission, suggesting that mental illness may have led to homelessness in these patients (Tidmarsh \& Wood, 1972). Although direct evidence is scant in the UK, it is felt that the closure of long-stay psychiatric hospitals could lead to some of their in-patients becoming homeless.

The single homeless are vulnerable to frequent physical and psychiatric ill-health (Scott et al, 1966). Their lifestyle makes it difficult for them to integrate or be integrated into the usual pathways of health care. Many of these patients, despite their need for medical and psychiatric treatment, are withdrawn and introspective, failing to come to the attention of social service and medical teams.

\section{The study}

We describe a drop-in psychiatric clinic at Great Chapel Street Medical Centre (GCSMC) in Soho, central London where an open-access general practice surgery has been in operation for over 11 years (El Kabir, 1982). We study 260 new patients seen between June 1984 and May 1987, and assess whether the service is an effective option in the care of such individuals. The administrator recorded demographic data. Medical details were recorded in a semi-structured interview by the psychiatrist and diagnoses were made in accordance with the International Classification of Diseases, ninth revision. Verification of data with hospital records was sought in all those with a history of psychiatric in-patient care (148 cases) and obtained in $90 \%$ (133 cases).

In assessing the value of a psychiatric clinic, sustained follow-up of patients is an important indicator. This is particularly true of a population as transient as the single homeless, many of whom have been lost to previous psychiatric care. We assess both the follow-up at the clinic and whether the schizophrenic patients had recently been under psychiatric care. Five or more attendances were taken to indicate initial commitment to the clinic by the patients (long attenders). Schizophrenic patients were considered lost to follow-up if they had not had contact with psychiatric services in the six months prior to presentation at our clinic.

One three hour session a week was held with an average of six patients attending per session. The majority of patients were referred from general practitioners. Other referrals came from hostels or probation services. There was no appointment system; patients were free to reattend when they wished.

\section{Findings}

The patients we encountered are typical of a single homeless population. They were predominantly single males ( $89 \%$ male, $79 \%$ single), often from the North of England, Scotland or Ireland (56\%). The age range was 14 to 71 years, although half fell in the 25 to 34 bracket; $20 \%$ were sleeping rough and $62 \%$ were hostel dwellers on presentation; $82 \%$ had had previous contact with psychiatric services.

The commonest diagnosis we encountered was schizophrenia $(24 \%)$, followed by personality disorder and alcohol dependence at $20 \%$ and $17 \%$ respectively. Neurotic disorder and drug dependence constituted the majority of the remaining illness. This contrasts with the picture that is more usually seen in psychiatric clinics in a general practice setting where neurotic illness in middle aged women predominates (Tyrer, 1984). 
The patients who appeared to benefit most from the clinic were suffering from schizophrenia. Their reattendance rate was significantly higher than nonschizophrenic patients. Out of 63 schizophrenic patients, 30 became long attenders compared to 65 out of 197 non-schizophrenic patients $\left(\chi^{2}=5\right.$, $P<0.025)$. It was felt that the open access policy was pivotal in this respect. The mental state of many of these patients was stabilised or improved. It is likely that some would have deteriorated rapidly without psychiatric care, eventually requiring hospital admission. Of the chronic schizophrenic patients, 37 $(59 \%)$ had not been receiving psychiatric care for six months prior to their first consultation with us, suggesting that they had been lost to previous follow-up. Despite this about half became long attenders at our clinic.

Sixty-two per cent were initially managed at the clinic; $8 \%$ were admitted voluntarily to hospital; $8 \%$ to a detoxification unit and $5 \%$ to our sick bay. Over half of patients attended only once. There are many factors underlying this. Our non-prescribing policy for opiates and reluctance to prescribe benzodiazipines except on a short-term basis was undoubtedly unattractive to some. Others had only self-limiting problems, in particular those with neurosis or personality disorder in crisis, and follow-up in such cases would not be expected. However, we were also aware that some mentally ill homeless did not reattend more out of choice than for obvious external reasons. It is also likely that despite the ease of access to our clinic some homeless would still not attend.

It is not unique for psychiatrists to work in a general practice setting and this is usually found to be satisfactory. This system has many advantages in dealing with the single homeless. Referrals can be made quickly to a psychiatrist who is personally known to the staff. The familiarity of the patients with the medical centre and its staff helps to reduce their fear of meeting a psychiatrist as he is seen as being part of the same team. Patients are sometimes reluctant to be referred to a psychiatric outpatient clinic. The informality of our clinic avoids some of these problems including the feeling of stigmatisation felt at seeing a psychiatrist in a hospital.

\section{Comment}

A drop-in psychiatric clinic, based on a pragmatic, flexible and responsive approach can significantly enhance the quality of medical service offered to the single homeless in a primary care setting. Schizophrenic patients in particular appear to benefit. The model may be replicable in other centres.

\section{References}

EL-KABIR, D. J. (1982) Great Chapel Street Medical Centre. British Medical Journal, 284, 1679.

LODGE-PATCH, I. C. (1971) Homeless men in London. 1. Demographic findings in a lodging house sample. British Journal of Psychiatry, 118, 313-317.

SCOTt, R., GASKell, P. \& Morrell, D. C. (1966) Patients who reside in common lodging houses. British Medical Journal, ii, 1561-1564.

Tidmarsh, D. \& WoOD, S. (1972) Psychiatric aspects of destitution. In Evaluating a Community Psychiatric Service: The Camberwell Register 1964-1971 (eds. J. K. Wing and A. M. Hailey). Oxford: Oxford University Press.

TYRER, P. (1984) Psychiatric clinics in general practice. British Journal of Psychiatry, 145, 9-14.

\section{Consumer satisfaction with a psychiatric out-patient clinic}

\section{A. JAWAD SheikH, Senior Registrar; and Christopher MEAkIn, Senior Registrar, Midland Nerve Hospital, Elvetham Road, Edgbaston, Birmingham B15 2NJ}

NHS out-patient clinics remain a major point of contact between psychiatrists and their patients. There are several advantages to this setting for consultation: it is time efficient, there is usually easy access to case records and contact with other disciplines and services is often available. With the 